\title{
Exercise is safe and beneficial for people with facioscapulohumeral muscular dystrophy
}

Robin L. Brey, MD

\begin{abstract}
What is facioscapulohumeral muscular dystrophy (FSHD)? FSHD is one of the most common types of muscular dystrophy. It causes weakness primarily in the muscles of the face, shoulders, upper arms, chest, abdomen, lower legs, and hips. Most people with FSHD have a form that runs in families. More information about FSHD can be found on the next page.
\end{abstract}

\section{Is exercise a good thing for people with FSHD?}

Muscle weakness is a major symptom in people with all different forms of muscular dystrophy. This can make it difficult to exercise. Exercise has many health benefits, which include having a healthy heart, strong bones, more energy, and a better outlook on life. There have been some reports of certain types of exercise causing damage to already weak muscles in people with muscular dystrophy. A study reported in this issue of Neurology by Olsen et al. ${ }^{1}$ showed that exercise can be safe and beneficial for people with FSHD.

\footnotetext{
How was this study done? Over a 12-week period, the researchers studied two groups of people: 1) eight people with FSHD (four men and four women) who were not severely affected; and 2) seven healthy people (four men and three women). All of the people with FSHD had weakness in their faces and arms. Four of them also had weakness in their legs. All of the healthy people had normal muscle strength, but did not exercise regularly.
}

Both groups were tested for their level of physical fitness at the beginning of the study and after the exercise-training period. A muscle biopsy was also done before and after training. The muscle was examined for any evidence of damage that could have resulted from the exercise program. A blood test for muscle damage was also done before and after the exercise program.

All study participants trained on a stationary bicycle for a 35-minute session five times each week for 12 weeks. This program was designed to create a low intensity aerobic workout. Following training, study subjects were asked about any changes in their muscle strength, ability to walk, stamina, activity level, and fatigue.

\section{What did the study show?}

All but one of the study participants was able to keep to the training schedule. Training increased the measures of physical fitness in both groups. No muscle damage occurred as a result of training in either group. In fact, in both groups there was a slight increase in small blood vessels called capillaries in the muscles after the training program. This is a positive effect of exercise on the muscles. Most people with FSHD felt that participating in the exercise training program lead to an improvement in their strength, stamina, activity level, and fatigue. This benefit was seen in both men and women.

\section{What do the results of this study mean?}

This study showed that low intensity aerobic training is safe and im- proved physical fitness in people with FSHD. The exercise program did not cause muscle damage. In both groups, exercise had a positive effect on the muscles by increasing the number of capillaries in the muscles. This is important because the amount of blood going to muscles during exercise helps determine a person's level of stamina and endurance during exercise. An increase in blood flow to the muscles helps improve stamina and endurance with exercise training. This study showed that muscles of people with FSHD could respond in this normal way to exercise.

\section{Are there any limitations of this study?}

The number of people participating in this study was small. Also, the people with FSHD who participated were only mildly weak. It is possible that if more people with FSHD who had more severe weakness had participated, the researchers might have gotten different results. The results are exciting, however, more studies should be done to learn about the benefits or potential harm of exercise in people with FSHD at different stages of the disease.

\section{What does this study mean to me?}

If you are a person with FSHD, you should talk with your doctor about exercise. There are many potential benefits from being as physically fit as possible. It is important that you choose the exercise program is right for you 


\section{What is FSHD?}

Facioscapulohumeral muscular dystrophy (FSHD) is the third most common form of muscular dystrophy, occurring in one out of every 20,000 people in the United States. People with FSHD develop muscle weakness involving the face, shoulders, upper arms, chest, abdomen, lower legs, and hips. The muscle weakness usually gets worse with time. The rapidity and extent of muscle loss is quite variable among people with FSHD.

\section{Who gets FSHD?}

FSHD usually begins in childhood, and before the age of 20 in $95 \%$ of people.

\section{What causes FSHD?}

An abnormality in a gene (called a deletion) causes FSHD. Most people who have the disease inherited the gene deletion from a parent. A gene deletion is passed from parent to child in a way that is called "autosomal dominant inheritance." This means that the parent (mother or father) with the gene deletion has a $50 \%$ chance of passing it to a child. Both sons and daughters are equally likely to be affected. Most people with the gene deletion develop symptoms; however, as many as one-third never develop the symptoms of FSHD. It is possible for an affected child to have normal parents for one of three reasons: 1) the parent with the gene deletion does not have symptoms; 2) a parent may have a very rare genetic condition in which all the cells in their body do not have the same genetic content; he or she may not have symptoms but can pass on FSHD if their sex cells happen to contain the deletion; or 3) neither parent has the gene deletion and it occurred spontaneously in the child. A spontaneous mutation only happens in 10 to $30 \%$ of people with FSHD.

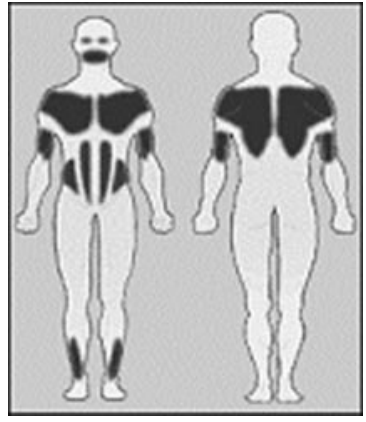

Figure. Muscles affected in people with facioscapulohumeral muscular dystrophy.

\section{What are the symptoms of FSHD?}

The symptoms of FSHD usually begin in the face or shoulder girdle muscles. The lower facial muscles usually are more affected than the upper ones. This leads to difficulties with activities like whistling or turning up the corners of the mouth when smiling. The shoulder muscles become very weak in most people with FSHD. The shoulder blades become unstable and cannot give the arms the support they need in lifting the arms up. When this happens the shoulder blades are said to "wing out" with arm movement. The pectoral and abdominal muscles may become weak. The legs may or may not be weak. The breathing muscles are usually normal. The figure illustrates the muscles that are usually affected in FSHD.

Other symptoms of FSHD can include hearing loss, eye problems, and very rarely, mild mental retardation. In most instances FSHD does not lead to any effects on mental abilities. The heart and internal (smooth) muscles are not affected. Progression of muscle weakness is usually slow and continuous. The severity of the weakness is highly variable from person to person, even within families. The size of gene deletion that causes FSHD is different in different families. People with large gene deletions seem to have the most severe muscle weakness and wasting. Many patients describe an up-and-down course with periods of stability followed by periods of rapid deterioration. About 20\% of affected individuals require a wheelchair. Life expectancy is not shortened for people with FSHD.

\section{How is FSHD diagnosed?}

The diagnosis of FSHD is suspected in individuals with muscular weakness of the face, shoulders, arms, hip girdle, and lower legs that develops before the age of 20 . There is a test that can be done to see if the gene deletion known to cause FSHD is present. There are no other particular laboratory tests that make the diagnosis of FSHD, but they can be helpful in excluding other diagnoses.

\section{How is FSHD treated?}

There is no cure and no specific treatment for FSHD at this point in time. The treatment options that are available are limited to those that treat some of the symptoms. In some cases, surgery and assistive devices are used to correct for muscle weakness. Physical therapy, braces and supports may be helpful. An exercise regimen may be helpful, but we are uncertain of the long-term consequences of muscle exertion especially in people who are severely affected by the disease. You should speak with a neurologist about the options that are currently available.

\section{For more information}

American Academy of Neurology www.aan.com

American Academy of Neurology Foundation www.thebrainmatters.org

\section{Reference}

1. Olsen DB, Ørngreen MC, Vissing J. Aerobic training improves exercise performance in facioscapulohumeral muscular dystrophy. Neurology 2005;64:1064-1066. 


\section{Neurology}

\section{Exercise is safe and beneficial for people with facioscapulohumeral muscular dystrophy Robin L. Brey \\ Neurology 2005;64;E22 \\ DOI 10.1212/WNL.64.6.E22}

\section{This information is current as of March 21, 2005}

\section{Updated Information \&} Services

References

Permissions \& Licensing

Reprints including high resolution figures, can be found at: http://n.neurology.org/content/64/6/E22.full

This article cites 1 articles, 1 of which you can access for free at: http://n.neurology.org/content/64/6/E22.full\#ref-list-1

Information about reproducing this article in parts (figures,tables) or in its entirety can be found online at: http://www.neurology.org/about/about_the_journal\#permissions

Information about ordering reprints can be found online: http://n.neurology.org/subscribers/advertise

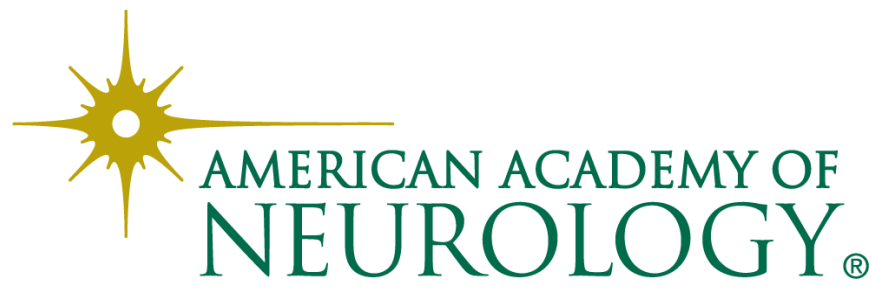

